\title{
Anthropometry-based Body Fat Percentage Predicts High hs-CRP in Chronic Kidney Disease Patients
}

\author{
Mochammad Thaha, ${ }^{1,2}$, Maulana Antiyan Empitu ${ }^{3, *}$, Ika Nindya Kadariswantiningsih ${ }^{4}$, \\ Cahyo Wibisono Nugroho ${ }^{1,2}$,Nurina Hasanatuludhhiyah ${ }^{3}$, Haerani Rasyid ${ }^{5}, Z_{\text {Zaky El Hakim }}^{6}$, \\ Maulana Muhtadin Suryansyah ${ }^{6}$, Rieza Rizqi Alda ${ }^{6}$, Mohammad Yusuf Alsagaff ${ }^{7,8}$, \\ Mochammad Amin ${ }^{9}$, Djoko Santoso ${ }^{1}$, Yusuke Suzuki ${ }^{10}$ \\ ${ }^{1}$ Department of Internal Medicine, Faculty of Medicine, Universitas Airlangga, Jl. Mayjen Prof. Dr. Moestopo 47, Surabaya, Indonesia \\ ${ }^{2}$ Department of Internal Medicine, Universitas Airlangga Hospital, Jl. Mulyorejo, Surabaya, Indonesia \\ ${ }^{3}$ Department of Pharmacology and Therapeutics, Faculty of Medicine, Universitas Airlangga, Jl. Mayjen Prof. Dr. Moestopo 47, Surabaya, Indonesia \\ ${ }^{4}$ Department of Medical Microbiology, Faculty of Medicine, Universitas Airlangga, Jl. Mayjen Prof. Dr. Moestopo 47, Surabaya, Indonesia \\ ${ }^{5}$ Department of Internal Medicine, Faculty of Medicine, Universitas Hasanudin, Jl. Perintis Kemerdekaan Km. 10, Makassar, Indonesia \\ ${ }^{6}$ Medical Science Program, Faculty of Medicine, Universitas Airlangga, Jl. Mayjen Prof. Dr. Moestopo 47, Surabaya, Indonesia \\ ${ }^{7}$ Department of Cardiology and Vascular Medicine, Faculty of Medicine, Universitas Airlangga, Jl. Mayjen Prof. Dr. Moestopo 47, Surabaya, Indonesia \\ ${ }^{8}$ Department of Cardiology and Vascular Medicine, Universitas Airlangga Hospital, Jl. Mulyorejo, Surabaya, Indonesia \\ ${ }^{9}$ Institute of Tropical Disease, Universitas Airlangga, Jl. Mulyorejo, Surabaya, Indonesia \\ ${ }^{10}$ Department of Nephrology, Juntendo University Faculty of Medicine, 2-1-1 Hongo Bunkyo-ku, Tokyo, Japan \\ ${ }^{*}$ Corresponding author. E-mail: mochthaha@yahoo.com
}

Received date: Oct 20, 2017; Revised date: May 29, 2018; Accepted date: June 5, 2018

\section{Abstract}

$\mathrm{B}$ ACKGROUND: Obesity is an important cardiovascular risk factor and associated with low grade inflammation in chronic kidney disease (CKD) patients. This study aims to assess the association between body fat with serum high sensitivity C-reactive protein (hs-CRP) level in CKD patients.

METHODS: A cross-sectional study was performed in 71 CKD patients. Anthropometric measurements included body weight, height, body mass index (BMI), body fat percentage (BFP), skinfold thickness (SKF) of triceps and biceps were performed by trained physician. BFP was calculated using Kwok's Formula and hs-CRP was measured by Particle enhanced Turbidimetry.
RESULTS: The averaged BMI of our subjects was 25.8 \pm 4.4. There was no significant difference in BMI between pre-dialysis and hemodialysis CKD patients. Positive correlation was found between BFP and hs-CRP $(\mathrm{r}=0.266 ; p<0.05)$, while there was no significant correlation between BMI and hs-CRP.

CONCLUSION: Body fat percentage was associated with hs-CRP. Hence, it will be more beneficial to assess nutritional status in CKD using BFP rather than BMI alone since it was demonstrated to correlate with hs-CRP in our study.

KEYWORDS: CKD, obesity, inflammation, body fat, hs-CRP

Indones Biomed J. 2018; 10(2): 184-91

\section{Introduction}

In last decades, chronic kidney disease (CKD) has been one of the global health problems with high morbidity and mortality rates. The prevalence of CKD in United States was around $6-10 \%$ of adult population with mortality rate 20 $50 \%$.(1) In Indonesia, the prevalence of CKD was $10 \%$.(2) Chronic kidney disease is a progressive disease with wide spectrum of manifestations, from mild decreased kidney function denoted by micro albuminuria to chronic renal failure with necessity for renal replacement therapy.(3) 
Obesity is an important CKD risk factor with high prevalence in general population. $(4,5)$. Study by Kelly, et al., estimated 937 million or $23.2 \%$ of the world's adult population was overweight and 396 million (9.8\%) was obese. $(6,7)$ They also projected the absolute numbers of overweight and obese individuals in 2030 will increase to be 2.16 billion and 1.12 billion, respectivley.(7) In 2010, overweight and obesity were estimated to cause 3.4 million deaths, $3.9 \%$ of years of life lost, and $3.8 \%$ of disabilityadjusted life-years (DALYs) worldwide.(8) Available data show that the most dramatic increases in obesity are in developing countries such as Mexico, China, and Thailand. $(9,10)$

Inflammation is considered as one of the key elements in almost all of kidney diseases. In CKD, particularly in patients with end-stage renal disease (ESRD), prevalence of chronic low-grade inflammation is quite high. One of the potential causes of low-grade inflammation in CKD patients is excess of adipose tissue. Recently, adipose tissue is considered as an endocrine organ and major site that plays important role for inflammatory and metabolic pathways.(11) The adipose tissue is a complex organ with functions other than energy storage, and secretes several adipokines, such as tumor necrosis factor (TNF)- $\alpha$, interleukin (IL)-6, type 1 plasminogen activator inhibitor (PAI-1), C-reactive Protein (CRP), resistin, and acylationstimulating protein.(12) In the human body, the major fat deposit sites are subcutaneous fat and visceral abdominal fat. Both of the fat deposit sites stated previously are associated with insulin resistance and pro inflammation in obese subjects.(11)

Excess of adipose tissue and chronic inflammation are associated with early pathogenesis of kidney injury, such as glomerular hyperfiltration. Moreover, a harmful renal hemodynamic profile is also linked to obesity both in patients with ESRD and general population. Patients with advanced CKD had increased expression of proinflammatory genes in their subcutaneous abdominal fat. This provides evidence that obesity in CKD also associated with inflammation at the cellular level.(13) Positive association also found between total body fat, abdominal body fat, and markers of inflammation not only in general population but also in CKD patients. $(11,12)$

High-sensitivity CRP (hs-CRP) is a most frequently used marker of inflammation. CRP does not show a significant circadian variability in stable condition, and its stability in laboratory measurements is comparable to serum cholesterol levels. This biomarker also associated with higher risk of cardiovascular events and mortality.
$(14,15,16)$ The objective of this study was to assess the association between body fat percentage (BFP) with serum hs-CRP level in CKD patients. This study compared the ability of BFP with widely used body mass index (BMI) to predict the value of serum hs-CRP in CKD patients. Considering these findings that link body fat with the presence of inflammation, we hypothesized that higher body fat are associated with elevated serum hs-CRP in CKD patients.

\section{Methods}

\section{Study Design and Population Selection}

This was an analytic observational study using crosssectional design. Ninety patients from outpatient clinics and hemodialysis (HD) units at two government and a private hospitals in Surabaya and Makasar were recruited from May to July 2017. This study was approved by Ethical Committee \& Law of Universitas Airlangga Hospital with No. 093/KEH/2017.

Seventy three patients were diagnosed with CKD. Seventy one patients were qualified to participate in this study since 2 patients were excluded due to acute inflammatory conditions. The inclusion criteria were adult CKD patients, aged $>21$ years old and agreed to participate in this study. The diagnosis of CKD was confirmed by National Kidney Foundation Kidney Disease Outcomes Quality Initiative (NKF K-DOQI) criteria based on Chronic Kidney Disease Epidemiology Collaboration (CKD-EPI) equation (estimated glomerular filtration rate (eGFR) $\leq 60$ $\mathrm{mL} / \mathrm{min} / 1.73 \mathrm{~m}^{2}$, urine albumin $>300 \mathrm{mg} /$ day, albumin to creatinine ratio $(\mathrm{ACR})>250 \mathrm{mg} / \mathrm{g}$ for men and $>355 \mathrm{mg} / \mathrm{g}$ for women). Exclusion criteria were overt infection, fever in the last 3 days, signs of infection, acute inflammatory disease and malignancy.

\section{Anthropometric Measurement}

Anthropometric measurements, included body weight, height, BMI, BFP, skinfold thickness (SKF) of triceps and biceps were performed by trained physician. Body weight was measured to the nearest $0.1 \mathrm{~kg}$ in balance-beam scale. Height was measured to the nearest $0.5 \mathrm{~cm}$ while patients standing erect with their head in plane. BMI was calculated using formula of body weight $(\mathrm{kg})$ divided by square of height $\left(\mathrm{m}^{2}\right)$. SKF was measured using Lange skinfold caliper on the left arm or on the arm contrary to arteriovenous fistule for patients underwent hemodialysis. BFP was calculated using Kwok’s Formula: 
$\mathrm{BFP}=-27.149+6.137(\mathrm{SexB})+1.120(\mathrm{BMI})+17.308 \log 10($ Sum 2$)$

Notes: SexB, female $=2$, male $=1$; Sum 2, triceps + biceps.(17)

\section{Laboratory Parameters}

Blood and urine samples were collected early in the morning. Measurement of kidney function parameters (estimated glomerular filtration rate (eGFR), urine ACR, serum creatinine, serum cystatin-C) were performed using routine laboratory methods. High-sensitivity CRP was measured by Particle enhanced Turbidimetry (Roche Diagnostic, California, USA)

\section{Statistical Analysis}

Normality test was performed using Shapiro Wilk. For normally distributed variables, data were shown as mean \pm SD. For skewed variables, data were shown as median and interquartile range (1st quartile-3rd quartile). Correlation between variables was performed using Pearson correlation test. Receiver operating characteristic (ROC) curve were plotted using absolute value of BFP and hs-CRP value (high hs-CRP $>3 \mathrm{mg} / \mathrm{L}$ ). Optimal cut-off was defined as BFP value with highest cumulative value of sensitivity and specificity.

All testing were two-tailed at the 0.05 significance level. The statistical analyses were performed using XLSTAT software version 2016.02.28451.

\section{Results}

\section{Characteristic of Study Participants}

Seventy one patients were evaluated in this study (median age 59, 41 male). The baseline characteristics of study participants were depicted in Table 1 . The median of eGFR was $20 \mathrm{~mL} /$ minute $/ 1.73 \mathrm{~m}^{2}$. From anthropometric data, it was shown that the averaged BMI of our subjects was $25.8 \pm 4.4$. Overweight and obesity prevalence were $42 \%$ and $14 \%$ respectively. Only $2(3 \%)$ subjects were undernourished. The majority of subjects had some cardiometabolic diseases, such as $73 \%$ have type 2 diabetes mellitus, $87 \%$ percents have hypertension and $41 \%$ have congestive heart failure (CHF).

\section{Comparison of Characteristic between Non-HD and HD Patients}

The comparison between non-HD and HD patients characteristic was depicted in Table 2. There were no significant differences in age and sex ratio between nonHD and HD patients. There were significant differences
Table 1. Characteristics of study participants.

\begin{tabular}{lc}
\hline \multicolumn{1}{c}{ Characteristic } & $\begin{array}{c}\text { CKD HD and Non-HD } \\
(\mathbf{n}=71)\end{array}$ \\
\hline Age (years) & $59(53-63)$ \\
Sex ratio $(\mathrm{M} / \mathrm{F})$ & $41 / 30$ \\
\hline Kidney Function & \\
eGFR $\left(\mathrm{mL} /\right.$ minute $\left./ 1.73 \mathrm{~m}^{2}\right)$ & $20(3-39)$ \\
Urine ACR & $408(19-2174)$ \\
Serum Creatinine $(\mathrm{mg} / \mathrm{L})$ & $2.9(1.7-12.7)$ \\
Serum Cystatin-C $(\mathrm{mg} / \mathrm{L})$ & $2.8(1.7-6.7)$ \\
HD, n $(\%)$ & $26(37)$ \\
\hline
\end{tabular}

\section{Anthropometry}

Body Fat Percentage (\%)

$19.1(16.0-24.0)$

Body weight $(\mathrm{kg})$

$67.0(54.4-76.9)$

BMI, $\left(\mathrm{kg} / \mathrm{m}^{2}\right)$

$25.8 \pm 4.4$

Biceps skinfold (cm)

$1.2(1.0-1.7)$

Triceps skinfold (cm)

2.3 (1.6-3.0)

\section{BMI Categories}

$18.5-24.9, \mathrm{n}(\%)$

$29(40.845)$

25-29.9, n (\%)

$30(42.254)$

$<18.5, \mathrm{n}(\%)$

$2(2.817)$

$>=30, \mathrm{n}(\%)$

$10(14.085)$

\section{Lipid parameters}

Total Cholesterols $(\mathrm{mg} / \mathrm{dL})$

$204(167-236)$

LDL Cholesterols (mg/dL)

HDL Cholesterols (mg/dL)

$39(13)$

\begin{tabular}{lc}
\hline Cardiovascular Disease and Risk Factors & \\
Type 2 Diabetes, n (\%) & $54(76)$ \\
Hypertension, n (\%) & $62(87)$ \\
High SBP, n (\%) & $26(37)$ \\
High DBP, n (\%) & $10(14)$ \\
CHF, n (\%) & $29(41)$ \\
hs-CRP (mg/L) & $1.8(1.1-4.3)$ \\
High hs-CRP, n (\%) & $24(34)$ \\
\hline
\end{tabular}

in kidney function parameters for eGFR, urine ACR, serum creatinine, serum cystatin-C between two groups. Those were, eGFR $(<0.0001)$, urine ACR $(<0.0001)$, serum creatinine $(<0.0001)$, serum cystatin-C $(<0.0001)$. Anthropometry measurement results mostly demostrated no significant differences. Those were for body fat percentage, body weight, BMI, and biceps skinfold. However, triceps skinfold of HD patients was significantly lower than non-HD patients $(p<0.05)$. Our study showed that the HD patients had significantly higher hs-CRP level than non-HD patients $(p<0.01)$. However there was no significant difference of the 
Table 2. Comparison of characteristic between non-HD and HD patients.

\begin{tabular}{|c|c|c|c|}
\hline Characteristic & $\begin{array}{c}\text { Non HD } \\
(n=45)\end{array}$ & $\begin{array}{c}\text { HD } \\
(n=26)\end{array}$ & $p$-value \\
\hline Age (years) & $58.13 \pm 5.92$ & $57.62 \pm 10.98$ & 0.9 \\
\hline Sex ratio $(\mathrm{M} / \mathrm{F})$ & $27 / 18$ & $14 / 12$ & 0.613 \\
\hline \multicolumn{4}{|l|}{ Kidney Function } \\
\hline eGFR (ml/minute $\left./ 1.73 \mathrm{~m}^{2}\right)$ & $29(22-60)$ & $3(2-4)$ & $<0.0001^{*}$ \\
\hline Urine ACR & $184(18-803)$ & $1789(834-3473)$ & $<0.0001^{*}$ \\
\hline Serum Creatinine (mg/dL) & $1.88(1.29-2.59)$ & $14.14(11.51-15.95)$ & $<0.0001^{*}$ \\
\hline Serum Cystatin-C (mg/L) & $1.88(1.28-2.61)$ & $7.42(6.58-7.94)$ & $<0.0001^{*}$ \\
\hline \multicolumn{4}{|l|}{ Anthropometry } \\
\hline Body Fat Percentage (\%) & $20.7 \pm 7.2$ & $18.7 \pm 7.9$ & 0.205 \\
\hline Body weight (kg) & $69(62.0-78.0)$ & $61.8(52.6-74.9)$ & 0.11 \\
\hline $\operatorname{BMI}\left(\mathrm{kg} / \mathrm{m}^{2}\right)$ & $26.31 \pm 4.25$ & $25.02 \pm 4.59$ & 0.254 \\
\hline Biceps Skinfold (cm) & $1.3(1.0-1.8)$ & $1.1(1.0-1.6)$ & 0.586 \\
\hline Triceps Skinfold (cm) & $2.4(2.1-3.1)$ & $1.8(1.3-2.8)$ & $0.026^{*}$ \\
\hline \multicolumn{4}{|l|}{ Lipid parameters } \\
\hline Total Cholesterols (mg/dL) & $215(182-245)$ & $189(151-206)$ & $0.013^{*}$ \\
\hline LDL Cholesterols (mg/dL) & $131 \pm 54$ & $105 \pm 34$ & $0.037^{*}$ \\
\hline HDL Cholesterols (mg/dL) & $44 \pm 15$ & $39 \pm 14$ & 0.237 \\
\hline \multicolumn{4}{|c|}{ Cardiovascular Disease and Risk Factors } \\
\hline Type 2 Diabetes, n (\%) & $41(91)$ & $15(58)$ & $0.001^{*}$ \\
\hline Hypertension, n (\%) & $39(87)$ & $26(100)$ & 0.337 \\
\hline High SBP, n (\%) & $6(13)$ & $20(77)$ & $<0.0001^{*}$ \\
\hline High DBP, n (\%) & $4(9)$ & $6(23)$ & 0.098 \\
\hline CHF, n (\%) & $15(33)$ & $14(54)$ & 0.09 \\
\hline hs-CRP (mg/L) & $1.40(0.90-3.20)$ & $2.10(1.65-8.05)$ & $0.010^{*}$ \\
\hline High hs-CRP, n (\%) & $12(26.67)$ & $12(46.12)$ & 0.094 \\
\hline
\end{tabular}

* : significant correlation

proportion of patients with high hs-CRP between non-HD and HD patients.

\section{hs-CRP Concentration in CKD Patients}

Positive correlation was found between BFP and hs-CRP $(\mathrm{r}=0.266 ; p<0.05)$ as shown in Table 3. However there was no significant correlation between BMI and hs-CRP.

\section{Comparison for BMI and BFP to Predict High hs-CRP} BFP and BMI may predict inflammation in our CKD patients with cut off point $18.4 \%$ (Figure 1, Figure 2). The BFP value above $18.4 \%$ were positively associated with high hs-CRP, indicated by significant crude and adjusted odd ratio (OR) (4.705 and 5.056 respectively). The crude OR of high hs-CRP was also significant for BMI (3.447).

Table 3. Pearson's matrix of association between BFP and hs-CRP.

\begin{tabular}{lcccc}
\hline \multirow{2}{*}{ Parameters } & \multicolumn{2}{c}{ hs-CRP } & \multicolumn{2}{c}{$\log$ hs-CRP } \\
\cline { 2 - 5 } & $\boldsymbol{p}$-value & $\begin{array}{c}\text { Correlation } \\
\text { Coefficient }\end{array}$ & $\boldsymbol{p}$-value & $\begin{array}{r}\text { Correlation } \\
\text { Coefficient }\end{array}$ \\
\hline BFP & $\mathbf{0 . 0 2 5 *}$ & $\mathbf{0 . 2 6 6}$ & $\mathbf{0 . 0 0 6 *}$ & $\mathbf{0 . 3 2 4}$ \\
BMI & 0.448 & 0.092 & 0.117 & 0.188 \\
Total Cholesterol & 0.129 & 0.182 & 0.728 & 0.042 \\
LDL Cholesterol & 0.099 & -0.197 & 0.117 & -0.188 \\
HDL Cholesterol & $\mathbf{0 . 0 0 4 *}$ & $\mathbf{- 0 . 3 4 1}$ & $\mathbf{0 . 0 0 1 *}$ & $\mathbf{- 0 . 3 7 8}$ \\
Ratio of Tota1/HDL Cholesterol & $<\mathbf{0 . 0 0 0 1 *}$ & $\mathbf{0 . 6 3 7}$ & $\mathbf{0 . 0 0 4 *}$ & $\mathbf{0 . 3 3 9}$ \\
\hline
\end{tabular}

* : significant correlation 


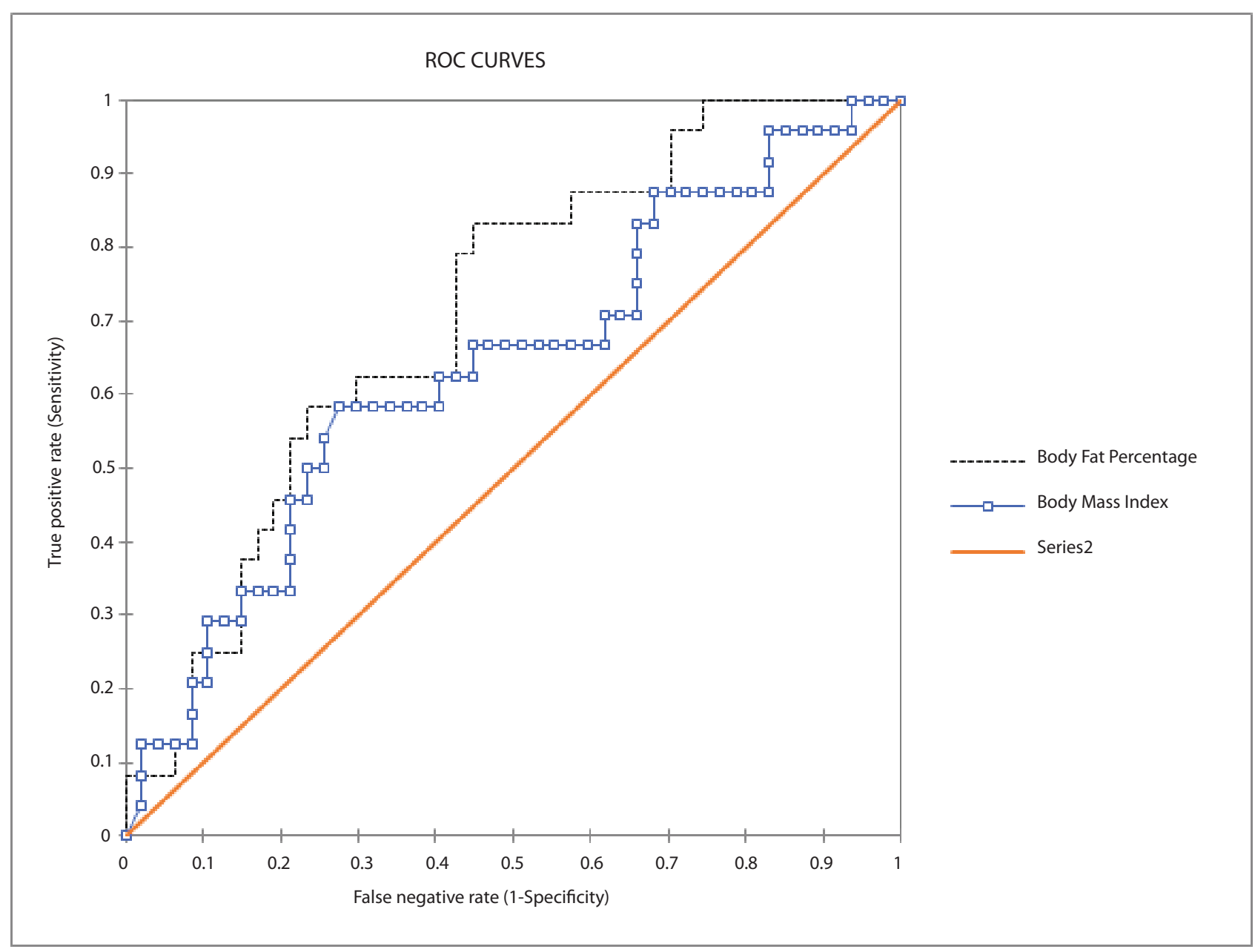

Figure 1. ROC curve of BFP and BMI to predict high hs-CRP $(p$-value $=0.001)$.

It remained significant after adjusted by age (3.487). The area under curve (AUC) of receiver operating characteristic (ROC) for BMI was lower than BFP (Table 4).

\section{Discussion}

Since there were no significant differences in age, sex, BMI, BFP, and the prevalence of high hs-CRP between non-HD and HD groups, we combined HD and non-HD groups in the sensitivity and specificity analysis of BFP and BMI to predict high hs-CPR. In this observational study, we demonstrated positive correlation between BFP and hs-CRP in CKD populations.

CRP is an established marker of systemic inflammation in the general population as well as patients with CKD. Inflammation plays fundamental role in pathophysiology of CKD and has beed linked with cardiovascular disease, protein energy wasting and mortality in CKD patients.(18) Our study showed that the HD patients group with significantly lower kidney function had significantly higher hs-CRP level than the non HD patients. Several studies has shown predictive values of hs-CRP in CKD. Persistently elevated hs-CRP level is associated with all cause mortality in ESRD. It is also considered as a predictor for malnutrition and cardiovascular disease in hemodialysis patients.(14)

The most prevalent nutritional status in our study was overweight (BMI 25-29.9). This was in line with the finding of a large cohort study conducted by Herrington, et al., which concluded that BMI $>25 \mathrm{~kg} / \mathrm{m}^{2}$ was associated with a progressively increased risk of CKD stages 4-5.(19) Prior studies also found high prevalence of overweight and obesity in predialysis and CKD patients. $(20,21)$ However, our study could not show correlation between BMI and hsCRP level. Several literatures have stated that BMI is less than ideal metric for obesity in CKD population.(22) Others also highlight the limitations of BMI as a reflection of body 


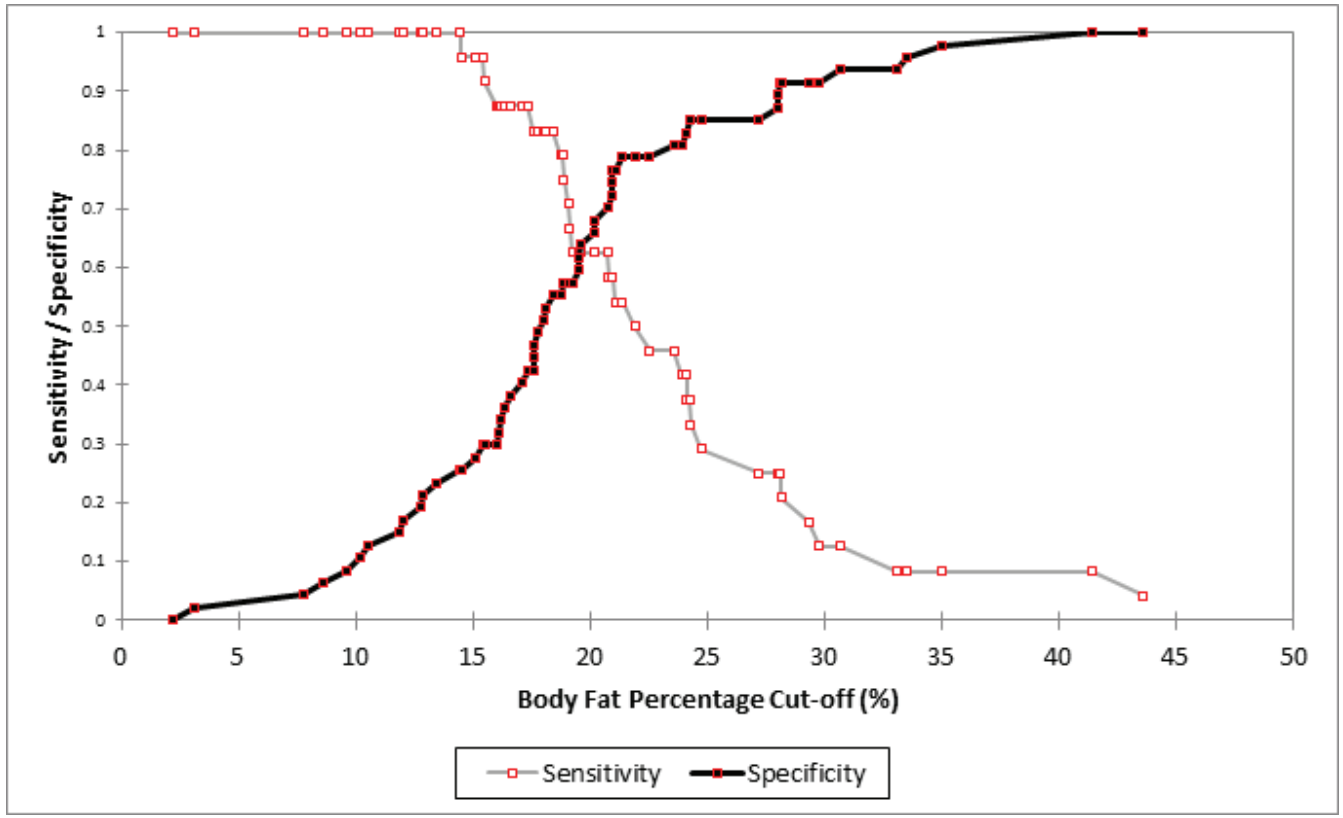

Figure 2. Sensitivity and specificity of body fat percentage for predicting high hs-CRP. composition (21), since it is unable to discriminate fat and muscle mass as well as hydration status which often alter in CKD patients. $(23,24)$ Therefore we also included BFP as anthropometric parameter other than BMI.

The correlation between BFP and hs-CRP in this study was concordance with previous study which demonstrate association between CRP and BFP measured by bioimpedance method in non dialysis stage 3-5 CKD patients. Inflammatory cytokines in CKD are produced not only by lymphocytes, but also by adipose tissue, which becomes dysfunctional in CKD (25) characterized by increased hs-CRP production (26). Additionally, this study observed that the hs-CRP also correlate negatively with HDL cholesterol and positively with total/HDL cholesterol ratio. Some previous extensive studies have shown that the impaired cholesterol metabolism was strongly correlated with increased inflammatory state in CKD patients.(27) The cholesterol profile was also correlated well with BMI and BFP, although not at the same degree of association compared to triglycerides.(27) Therefore theoretically, greater BFP and BMI would reflect as a higher cholesterol levels. In this study, the total/HDL cholesterol ratio was the strongest factor associated with hs-CRP levels compared to others lipid parameters as well as anthropometric parameters. However, this study failed to observe the association between laboratory lipid parameters with either BMI and BFP (data not shown).

We used anthropometry based BFP calculation using Kwok's formula. We assumed that the characteristics of subjects in Kwok's study were similar with our study.(28) Anthropometry based BFP is considered to be a valid discriminator for cardiometabolic risk in comparison with dual energy X-ray absorptiometry (DEXA) scan and Bioelectrical impedance analysis (BIA) methods, as shown by Krachler, et al., in general population.(29) This method is cheaper and easier compared to DEXA Scan and BIA.

Table 4. AUC, specificity, sensitivity, and OR (CI 95\%) of high hs-CRP value using BFP's optimal cut-off $18.4 \%$ and BMI cut-off $27.3 \mathrm{~kg} / \mathrm{m}^{2}$.

\begin{tabular}{lcccc}
\hline & \multicolumn{2}{c}{ BFP } & \multicolumn{2}{c}{ BMI } \\
\cline { 2 - 5 } & Test Value & CI 95\% & Test Value & CI 95\% \\
\hline AUC & 0.71 & $(0.592-0.828)$ & 0.637 & $0.501-0.774$ \\
Sensitivity & 0.833 & $(0.634-0.938)$ & $\mathbf{0 . 5 8 3}$ & $\mathbf{0 . 3 8 8 - 0 . 7 5 5}$ \\
Specificity & 0.553 & $(0.412-0.686)$ & $\mathbf{0 . 7 2 3}$ & $\mathbf{0 . 5 8 1 - 0 . 8 3 1}$ \\
Odds Ratio (Unadjusted) & 4.705 & $(1.560-14.192)$ & 3.447 & $1.247-9.530$ \\
Odds Ratio (Adjusted by Age) & 5.056 & $(4.343-5.885)$ & 3.487 & $3.046-3.992$ \\
\hline
\end{tabular}


The finding of this study should be viewed with some limitation. The small sample size of this study might not reflect accurately the predictive ability of BFP and BMI to estimate the value of hs-CRP. Specificity of hs-CRP was considered to be low since many factors may influence its measurement i.e., diabetes, infection, smoking, chronic diseases, sleep disorders, malnutrition, anemia, old age, alcohol consumption, CVD, hypertension, vascular access, pregnancy, pharmacological therapy, dialysis and CRP gene polymorphism, which this study did not estimate in the statistical analysis. Additionally, the relatively narrow range of BFP and BMI among the study participants may limit the ability of statistical analysis to generate prediction model for hs-CRP. Therefore, this study could demonstrate some degree of association between anthropometric-based BFP and hs-CRP but with poor correlation and predictive value. Another limitation regarding this study is its applicability aspect. The relatively poor correlation between BFP and hsCRP has limited the usability of the specificity, sensitivity, and predictive value generated from this study in the daily clinical practice. However, the association of BFP and hs-CRP showed in this study might indicate a potential relationship between the two variables, particularly when a significantly bigger sample size is introduced.

\section{Conclusion}

In overall, this study emphasized the need to regularly assess nutritional status in CKD using BFP rather than BMI alone since it demonstrated better association with hs-CRP in our study. It needs further study to evaluate larger and more heterogenous samples to explore malnutrition as a risk factor for chronic inflammation as well as cardiovascular complications in CKD patients.

\section{References}

1. Jha V, Garcia-Garcia G, Iseki K, Li Z, Naicker S, Plattner B, et al. Chronic kidney disease: global dimension and perspectives. Lancet. 2013; 382: 260-72.

2. Levin A, Tonelli M, Bonventre J, Coresh J, Donner JA, Fogo AB, et al. Global kidney health 2017 and beyond: a roadmap for closing gaps in care, research, and policy. Lancet. 2017; 390: 1888-917.

3. Andrassy KM. Comments on'KDIGO 2012 clinical practice guideline for the evaluation and management of chronic kidney disease'. Kidney Int. 2013; 84: 622-3.

4. Kovesdy CP, Furth S, Zoccali C. Obesity and kidney disease: hidden consequences of the epidemic. JEMDSA. 2017; 22: 5-11.
5. Ejerblad E, Fored CM, Lindblad P, Fryzek J, McLaughlin JK, Nyrén O. Obesity and risk for chronic renal failure. J Am Soc Nephrol. 2006; 17: 1695-702.

6. Arroyo-Johnson C, Mincey KD. Obesity Epidemiology Worldwide. Gastroenterol Clin North Am. 2016; 45: 571-9.

7. Kelly T, Yang W, Chen C, Reynolds K, He J. Global burden of obesity in 2005 and projections to 2030. Int J Obes. 2008; 32: 1431-7.

8. Ng M, Fleming T, Robinson M, Thomson B, Graetz N, Margono $\mathrm{C}$, et al. Global, regional, and national prevalence of overweight and obesity in children and adults during 1980-2013: a systematic analysis for the Global Burden of Disease Study 2013. Lancet. 2014; 384: 766-81.

9. Caballero B. The global epidemic of obesity: an overview. Epidemiol Rev. 2007; 29: 1-5.

10. Popkin BM, Gordon-Larsen P. The nutrition transition: worldwide obesity dynamics and their determinants. Int J Obes Relat Metab Disord. 2004; 28 (Supp1 3): S2-9.

11. Carvalho LK, Barreto Silva MI, da Silva Vale B, Bregman R, Martucci $\mathrm{RB}$, Carrero JJ, et al. Annual variation in body fat is associated with systemic inflammation in chronic kidney disease patients Stages 3 and 4: a longitudinal study. Nephrol Dial Transplant. 2012; 27: 1423-8.

12. Nihi MM, Manfro RC, Martins C, Suliman M, Murayama Y, Riella $\mathrm{MC}$, et al. Association between body fat, inflammation and oxidative stress in hemodialysis. J Bras Nefrol. 2010; 32: 11-7.

13. Witasp A, Carrero JJ, Heimburger O, Lindholm B, Hammarqvist F, Stenvinkel $\mathrm{P}$, et al. Increased expression of pro-inflammatory genes in abdominal subcutaneous fat in advanced chronic kidney disease patients. J Intern Med. 2011; 269: 410-9.

14. Abraham G, Sundaram V, Sundaram V, Mathew M, Leslie N, Sathiah V. C-Reactive protein, a valuable predictive marker in chronic kidney disease. Saudi J Kidney Dis Transpl. 2009; 20: 811-5.

15. Tsai YW, Lu MC, Lin YH, Lee YC, Li WC, Chen JY, et al. Combined body mass index with high-sensitivity $\mathrm{C}$-reactive protein as independent predictors for chronic kidney disease in a relatively healthy population in Taiwan. Eur J Clin Nutr. 2016; 70: 766-72.

16. Lacson E, Levin NW. Poor nutritional status and inflammation: C-reactive protein and end-stage renal disease. Semin Dial. 2004; 17: 438-448.

17. Chambers AJ, Parise E, McCrory J, Cham R. A comparison of prediction equations for the estimation of body fat percentage in non-obese and obese older Caucasian adults in the United States. J Nutr Health Aging. 2014; 18: 586-90.

18. Akchurin OM, Kaskel F. Update on inflammation in chronic kidney disease. Blood Purif. 2015; 39: 84-92.

19. Herrington WG, Smith M, Bankhead C, Matsushita K, Stevens $\mathrm{S}$, Holt $\mathrm{T}$, et al. Body-mass index and risk of advanced chronic kidney disease: Prospective analyses from a primary care cohort of 1.4 million adults in England. PloS one. 2017; 12: e0173515. doi: 10.1371/journal.pone.0173515.

20. Silva MIB, da Silva Lemos CC, Torres MRSG, Bregman R. Waistto-height ratio: an accurate anthropometric index of abdominal adiposity and a predictor of high HOMA-IR values in nondialyzed chronic kidney disease patients. Nutrition. 2014; 30: 279-85.

21. Johansen KL, Lee C. Body composition in chronic kidney disease. Curr Opin Nephrol Hypertens. 2015; 24: 268-75.

22. Mallamaci F, Tripepi G. Obesity and CKD progression: hard facts on fat CKD patients. Nephrology Dialysis Transplantation. 2013; 28(Suppl 4): iv105-8.

23. Mafra D, Guebre-Egziabher F, Fouque D. Body mass index, muscle and fat in chronic kidney disease: questions about survival. Nephrol Dial Transplant. 2008; 23: 2461-6. 
24. Cuppari L. Diagnosis of obesity in chronic kidney disease: BMI or body fat? Nephrology Dialysis Transplantation. 2013; 28(Suppl 4): iv119-21.

25. Akchurin M, Kaskel F. Update on inflammation in chronic kidney disease. Blood Purif. 2015; 39: 84-92.

26. Lin CC, Kardia SL, Li CI, Liu CS, Lai MM, Lin WY, et al. The relationship of high sensitivity C-reactive protein to percent body fat mass, body mass index, waist-to-hip ratio, and waist circumference in a Taiwanese population. BMC Public Health. 2010; 10: 579. doi: 10.1186/1471-2458-10-579.
27. Reiss AB, Voloshyna I, De Leon J, Miyawaki N, Mattana J. Cholesterol metabolism in CKD. Am J Kidney Dis. 2015; 66: 107182.

28. Kwok T, Woo J, Lau E. Prediction of body fat by anthropometry in older Chinese people. Obes Res. 2001; 9: 97-101.

29. Krachler B, Völgyi E, Savonen K, Tylavsky FA, Alén M, Cheng S. BMI and an anthropometry-based estimate of fat mass percentage are both valid discriminators of cardiometabolic risk: a comparison with DXA and bioimpedance. J Obes. 2013; 2013: 862514. doi: 10.1155/2013/862514. 